\title{
Askin's Tumor - A Rare Case Report and Literature Review
}

\author{
APARNA DAS, ${ }^{1}$ AHMED HOSSAIN, ${ }^{2}$ MARUF H. CHOWDHURY, ${ }^{3}$ H.M. MUSTAFIJUR RAHMAN, ${ }^{4}$ SHUMONA ZAHID, ${ }^{5}$
}

\begin{abstract}
:
Askin's Tumour (Synonym: Primitive Neuro-Ectodermal Tumor) is a rare neoplasm of the chest wall. In 1979 Askin and Rosai described an unique clinicopathological entity, characterised as a malignant small-cell tumour of the soft tissues of the chest wall in childhood and adolescence. We report on a case of a 30-year old male who had a massive tumour in the left thorax. The clinical symptoms were cough and increasing dyspnoea. The tumour was revealed as a Primitive Neuro-Ectodermal Tumor (PNET) compatible with ASKIN's Tumor by CT-guided fine needle aspiration. Immunohistochemical studies showed positive staining for CD99. In our case, radiotherapy followed by chemotherapy was given. Microscopy and immunohistological stain of the specific marker-neuron-specific enolase-are essential. Multimodal treatment allows a long-term survival, but often the prognosis is variable.
\end{abstract}

Keyword : Askin's Tumor, Neoplasm, PNET

\section{Introduction:}

Primitive Neuro-Ectodermal Tumors (PNET) are extremely rare, highly malignant neoplasms probably derived from the embryonal migrating neural crest cells, ${ }^{1}$ comprising about $1 \%$ of all sarcomas. ${ }^{2}$ It is a member of the family of "smallround cell tumors "first described by Arthur Purdy Stout in 1918. ${ }^{3}$ These neoplasms predominantly occur in children and adolescents with a wide age range of 4 to 61 years presenting as bone \& soft tissue masses. ${ }^{4}$ According to Batsakis et al (1996) classification PNET family of tumors are of three groups- CNS PNETs (tumors of Central Nervous System), Neuroblastoma(tumors of Autonomic Nervous System), Peripheral PNETs (tumor of tissues outside the Central and Autonomic Nervous System). ${ }^{5}$ Peripheral Primitive Neuro-Ectodermal Tumors (pPNET) localized in thoracopulmonary region have been defined as Askin's tumor due to the fact that it was first reported by Askin et al in 1979 in 20 children and adolescents with a mean age of 14 years. ${ }^{6}$ Sex distribution is still unclear although some literatures are suggestive of female predominance. In this case report, we present an Askin's tumor occurred in a 30year-old male. The patient was admitted with the complaints of low grade intermittent fever for 6 months, cough with sputum production for 5 months and painless swelling in the neck for 4 months. He developed progressive breathlessness and blood stained sputum for last 15 days.

1. Assistant Professor, Department of Medicine, DMCH.

2. Associate Professor, Department of Medicine, SSMCH.

3. Registrar, Department of Medicine, DMCH.

4. Assistant Registrar, Department of Medicine, DMCH

5. Intern ,Department of Medicine, DMCH

Correspondence: Dr. Aparna Das, Assistant Professor, Department of Medicine, DMCH, Dhaka
CT scan of chest showed a soft tissue lesion is seen in the right side of mediastinum with right sided pleural effusion. CT guided FNAC from the chest mass was suggestive of Primitive Neuro-Ectodermal Tumor (PNET) compatible with Askin's Tumor. Immunohistochemical studies showed positive staining for CD99. Being a rare variety of peripheral PNET every Askin's tumor cases should be documented and reported. In our knowledge these is the second reported case of Askin's tumor in Bangladesh. ${ }^{7}$

\section{Case Report:}

A 30-years-old non-smoker farmer was admitted to our hospital with the complaints of low grade intermittent fever for 6 months, cough with sputum production for 5 months and painless swelling in the neck for 4 months. He developed progressive breathlessness and blood stained sputum for last 15 days. Neck swellings were gradually increasing in size and neither painful nor any discharge was coming out of it. He lost about $25 \%$ of his precious weight within this period. He did not have any chest pain, joint pain and evening rise of temperature or night sweats. He did not have any history of contact with tuberculosis patient. His bowel and bladder habit is normal. He is normotensive and non-diabetic.

On examination, the patient had puffy face and was mildly anaemic, cyanosed. His neck veins were engorged, nonpulsatile and axillary, inguinal and cervical lymph nodes were enlarged and multiple in number. Largest lymph node was about $5 \mathrm{~cm}$ in diameter, discrete, firm in consistency and nontender. He had engorged collateral veins in the chest and anterior abdominal wall and the direction was from above downwards. His chest movement was restricted on the right side with shifted trachea to the left. Percussion note was stony dull from the right $2^{\text {nd }}$ intercostals space to downwards. Breath sound and vocal resonance were diminished over the same area. 
Laboratory investigations revealed complete blood count report of $\mathrm{Hb} \%$ - 9.9\%, Total count -15,600/L,(Neutrophil$87.8 \%$, lymphocyte- $10.5 \%$, platelet- $3.99 \times 10 / L$, ) and ESR$105 \mathrm{~mm}$ in $1^{\text {st }}$ hour. Peripheral blood film showed normochromic normocytic anaemia. Serum Alpha feto protein was $3.4 \mathrm{ng} / \mathrm{mg}$ (normal up to $400 \mathrm{U} / \mathrm{L}$ ) and beta HCG $0.00 \mathrm{mIU} / \mathrm{L}$, Sputum for AFB -Negative, X-ray chest P/A view showed right sided massive pleural effusion with underlying lung collapse. USG of whole abdomen revealed multiple enlarged LN in the mediastinum (Largest: 4.8 X 3.7 $\mathrm{cm}$ ) and single LN in the para-aortic region. Pleural fluid study showed normal findings with negative malignant cells and no organism detected on Gram stain and ZN staining and total protein was $44 \mathrm{gm} / \mathrm{dl}$. Pleural fluid ADA was 8.2 U/L(normal: up to $24 \mathrm{U} / \mathrm{L}$ ). FNAC of left supra-clavicular lymph node showed metastatic germ cell tumor. CT scan of chest showed a soft tissue lesion is seen in the right side of mediastinum with right sided pleural effusion. $\mathrm{CT}$ guided FNAC from the chest mass showed adequate cellular material containing malignant tumor cells arranged in the background of necrotic debris at rosette formation in some areas. The nuclear chromatic was finely dispersed with in conspicuous nucleoi and the tumor was compatible with lung primary, suggestive of Primitive Neuro-Ectodermal Tumor (PNET) compatible with ASKIN's Tumor. Immunohistochemical studies showed positive staining for CD99. So our final diagnosis was mediastinal Primitive Neuro-Ectodermal Tumor (PNET) (ASKIN'S Tumor) with distant metastasis with superior vena caval obstruction with pleural effusion. Initially he was treated symptomatically and radiotherapy was given to reduce the obstructive features then he was treated with chemotherapy.

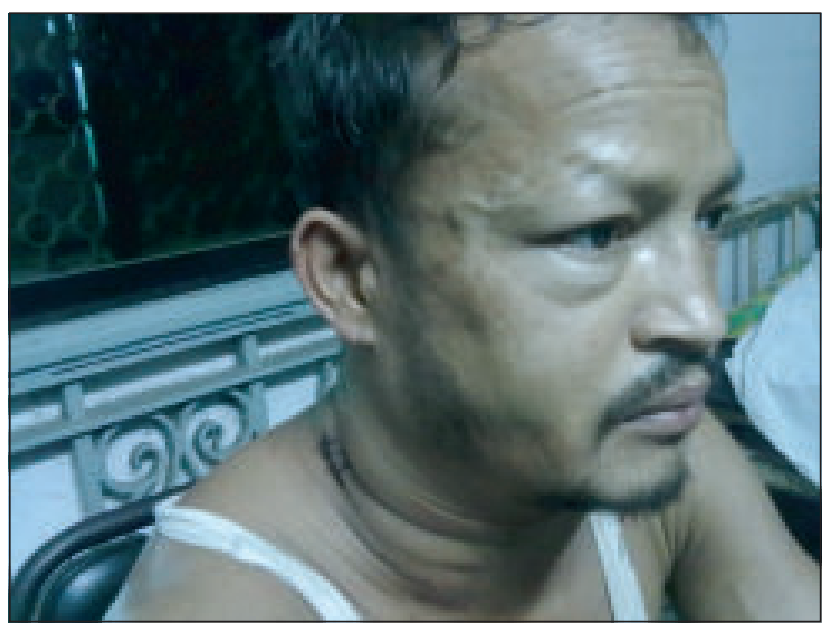

Fig-1: Showing SVC obstruction

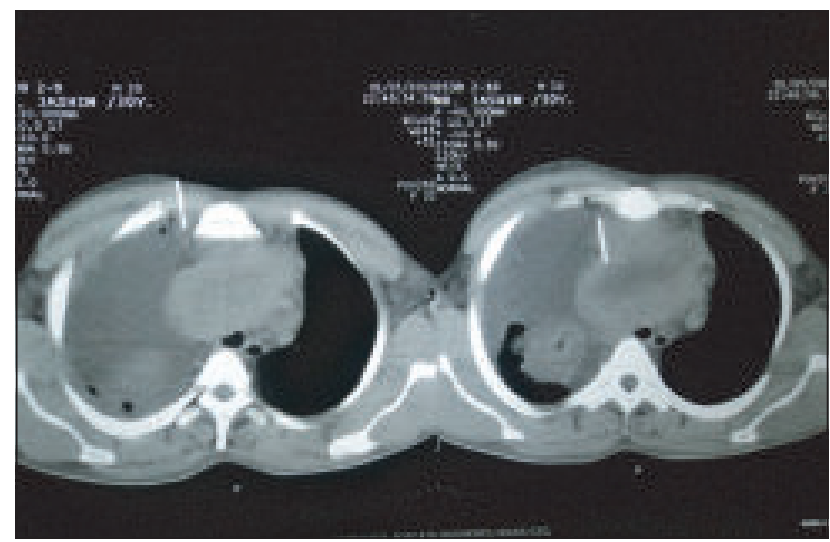

Fig-2: CT guided FNAC of the chest lesion

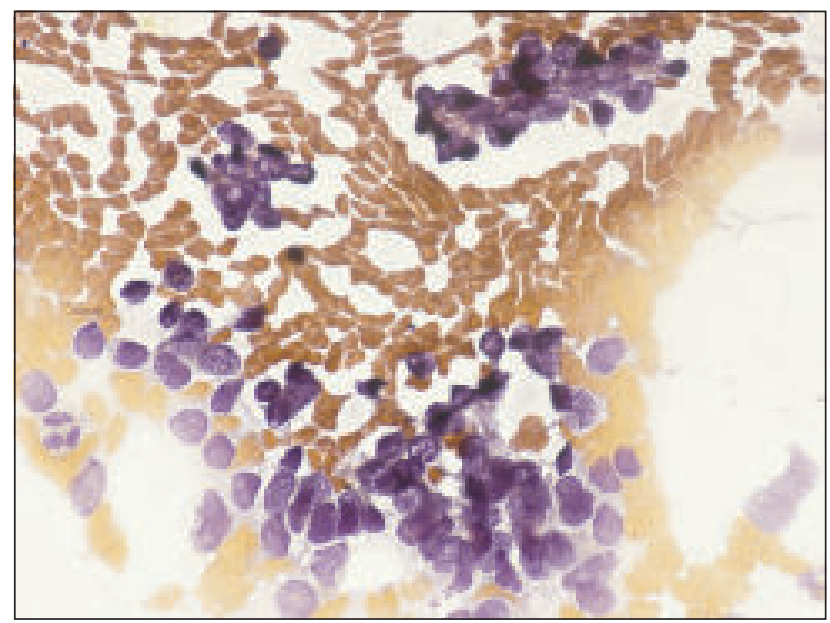

Fig.-3: Histological features suggestive of Small roundshaped cells with focal rosette formation.

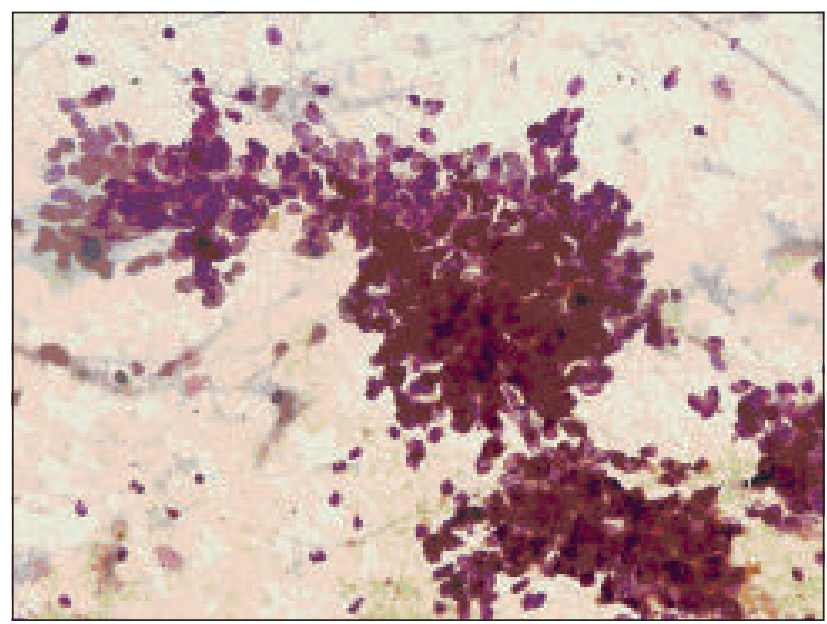

Fig.-4: Histological features suggestive of Small roundshaped cells with focal rosette formation.

\section{Discussion:}

PNET is a generic term used for a group of histologically indistinguishable small round blue cell tumors of neuroectodermal origin which are often neuron-specific enolase 
(NSE) positive. ${ }^{8}$ In 1921 this tumor was first described in bone by Ewing, which became known as Ewing Sarcoma. ${ }^{9}$ According to the new WHO classification, published in $2002,{ }^{10}$ the peripheral PNET including ASKIN's tumor and the Ewing Sarcoma are defined as identical tumors with separate differentiation in the neuro-ectoderm, because a characteristic chromosomal translocation $\mathrm{t}(11,22)(\mathrm{q} 24, \mathrm{q} 12)^{11}$ is found in more than $90 \%$ of peripheral PNET and Ewing Sarcoma. ${ }^{6}$ Primitive neuro-ectodermal tumors of CNS can be are of two types- infratentorial tumors (medulloblastoma or iPNET) and supratentorial tumors (sPNET). Metastatic spread of PNETs occurs mostly by Spinal dissemination via CSF. Supratentorial PNETs are more common in young adults and rarely occur (25:1) than the other variety. With a high local recurrence rate and early metastasizing capability to regional lymph nodes, lungs, liver, bone marrow peripheral primitive neuroectodermal tumors have a poor prognosis. Renal PNET is more aggressive than in the other sites. ${ }^{12}$ It frequently arises during childhood course towards metastatic disease and death. About 50 renal PNET cases have been documented in the English literatures. ${ }^{12}$ Mediastinal malignant lesions are more likely to produce signs and symptoms of obstruction, compression or both because they invade or transfix normal mediastinal structures. Invasion of the chest wall or pleura by a malignant neoplasm can produce persistent pleural effusion and a significant amount of local pain. Clinical features of PNET patients include cough, dyspnea, stidor, dysphagia, superor vena caval obstruction syndrome, hoarseness from recurrent laryngeal nerve paralysis, Systemic findings such as weight loss, fever and malaise. Pain is the only or main feature in $60 \%$ cases. Almost all features of PNET were present in our cases.

Askin's tumor (1.8\% of all mediastinal tumours $)^{13}$ develops as a solitary mass or multiple masses involving the thoracic wall and paravertebral structures most commonly arising from intercostal nerves ${ }^{14}$ and rarely affects the pulmonary parenchyma. In our case no neurological features are present.

Histopathology and immunohistochemical analysis is the main basis of diagnosis. The presence of MIC2 gene (a pseudoautosomal gene located on the short arms of the $\mathrm{X}$ and $\mathrm{Y}$ chromosome $)^{15}$ products, known as CD99, 12E7, E2, O13 and HBA71 suggested a PNET diagnosis. The typical histological feature for PNET is the Homer-Wright type rosettes. CD99 (glycoprotein P30/32) positivity is a very important clue for the diagnosis having $95 \%$ sensitivity. ${ }^{16}$ We got typical features of PNET in histopathology and CD99 positivity. The differential diagnoses from which Askin's tumor should be distinguished from Ewing Sarcoma, Rhabdomyocarcoma, Neuroblastoma and lymphoma. ${ }^{17}$

\section{Conclusion:}

A prompt multi disciplinary protocol incorporating neoadjuvant chemotherapy, surgery, and adjuvant chemotherapy should be started even though it is organ confined. In our case, initially he was treated symptomatically and radiotherapy was given to reduce the obstructive features then he was treated with chemotherapy followed by again chemotherapy. At the time of writing of this report the patient was improved and is under regular follow-up. As only very few Askin's tumor cases have been documented with a poor prognosis and no standard therapy is available for it. According to Contesso et al. the 2-year survival and 6-year survival rate was respectively $38 \%$ and $14 \%{ }^{8}$. Askin's report revealed that 14 of 18 patients with known prognosis died 4-44 months after diagnosis with a mean survival rate of 8 months. ${ }^{6}$

\section{Conflict of Interest : None}

\section{References :}

1. Reddy H, Yick D, Kamangar N. A case of primitive neuroectodermal tumor (PNET) of the chest wall in an adult. Chest 2009;136:325.

2. Enzinger F, Weiss S. Primitive neuroectodermal tumours and related lesions. In: Weiss SW, Enzinger FM (editors) Soft tissue tumours 3rd edition St Louis, MO: Mosby; 1995: 929-64. .

3. Sout A. A tumour of the ulnar nerve. Proc N Y Pathol Sco 1918;18:2-12.

4. Parham D, Roloson G, Feely M. Primary malignant neuroepithelial tumours of the kidney. Am J Surg Pathol 2001;25:133-46.

5. Batsakis JG MB, el-Naggar AK, et al. . Ewing's sarcoma and primitive neuroectodermal tumor; an interim report In: Ann Otol Rhinol Laryngol; Oct 1996:838-43.

6. Askin F, Rosai J, Sibley R. Malignant small cell tumor of the thoracopulmonary region in childhood. cancer 1979;43.

7. Hossain MS, Rahman AH, Faruque G, Hossen MM, Bari M, Das A. Askin's Tumor. Bang Onc J 2009;4:82-5.

8. Contesso G, Llombart-Bosch A, Tarrier P, Peydro-Olaya A, Henry AM, Oberlin O. Does Malignant Small Round cell tumor of the thoraco-pulmonary region(Askin Tumor) constitute a clinicopathologic Entity. cancer 1992;69: 1012-20.

9. Ewing J. Diffuse endothelioma of bone. Proc NY Pathol Soc 192 I;21:17-24.

10. Ushigome S, Machinami R, Sorensen P. Ewing sarcoma/ primitive neuroectodermal tumor (PNET). In: Fletcher CDM, Unni KK, Mertens F eds.; Pathology and Genetics of Tumours if Soft Tissue and Bone. . Lyon: IARC Press 2002:297-300. 
11. Delattre O, Zucman J, Plougastel B. Gene fusion with an ETS DNA- binding domain caused by chrosome translocation in human tumours. Nature 1992;359:162-5.

12. Lam J, Hensle T, Delbelenko L. Organ confined primitive neuroectodermal tumour arising from the kidney. J Pediatr Surg 2003;38:619-21.

13. Vaziri M, Pazooki A, Zahedi-Shoolami L. Mediastinal Masses: Review of 105 Cases. Acta Medica Iranica 2009;47:297-300.

14. Linnoi R, Tsoks M, Tirche T, Marangos P, Candra R. Evidence of neural origin and PSApositive variants of the malignant small cell tumor of thoracopulmonary region ('Askin tumor'). Am J Surg Pathol 1986;10:124-33.

15. Goodfellow P, Banting G, Sheer D. Genetic evidence that a Y-linked gene in man is homologous to a gene on the $\mathrm{X}$ chromosome. Nature 1983; 302:346-9.

16. Folpe A, Goldblum J, Rubin B, Shehata B, Liu W, Dei TA. Morphologic and Immunophenotypic Diversity in Ewing Family Tumors : A Study of 66 Genetically Confirmed Cases. Am J Surg Pathol 2005;29:1025-33.

17. Hage R, Duurkensvam, Seldenrijk C, la RBd, Swieten H, Bosch Jvd. Premitive neuroectodermal tumor: Report of two cases and review of the literature. J Thorac Cardiovasc Surg 2002;124:833. 